\title{
On the Oscillation of Combustion of a Laminar Spray
}

\author{
YESHAYAHOU LEVY* \\ Faculty of Aerospace Engineering, Technion-Israel Institute of Technology, Haifa 32000, Israel \\ DANIEL L. BULZAN \\ NASA Lewis Research Center, Cleveland, OH 44135

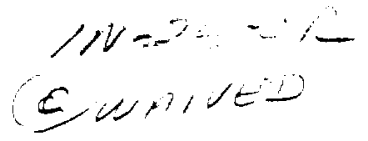

A spray combustor, with flow velocities in the laminar range, exhibits a unique operating mode where large amplitude, self-induced oscillations of the flame shape occur. The phenomenon, not previously encountered, only occurs when fuel is supplied in the form of fine liquid droplets and does not occur when fuel is supplied in gaseous form. Several fow mechanisms are coupled in such a fashion as to trigger and maintain the oscillatory motion of the flame. These mechanisms include heat transfer and evaporation processes, dynamics of two-phase flows, and effects of gravity (buoyancy forces). An interface volume, lying between the fucl nozzle and the flame was found to be the most susceptible to gravity effects, and postulated to be responsible for inducing the oscillatory motion. Heptane fuel was used in the majority of the tests.

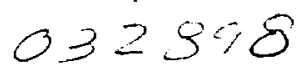

\section{INTRODUCTION}

The classical paper of Burke and Schumann [1] on gaseous diffusion flames is considered a milestone in the analysis of combustion processes. Although the authors made a number of simplifying assumptions in their model, including the neglect of gravity, constant gas and air velocities, and a constant diffusion coefficient for all species, their predictions were found to show relatively good agreement with experimental measurements. Gas composition and flame dimensions were predicted at various locations above the fuel nozzle. Other researchers [2-4] followed in their footsteps and improved the original model, but always retained the assumption that the fuel was supplied in gaseous form and neglected gravitational effects.

Various observations of a Burke-Schumann-type flame under laminar operating conditions revealed the phenomenon of flame tip flickering at frequencies of about $10-20 \mathrm{~Hz}$. This effect, which was observed experimentally

: [5-9] and also predicted numerically $[10,11]$, is the direct result of gravity-induced buoyant

* This work was performed while the first author held an NRC Research Associateship at Lewis Research Center.

COMBUSTION AND FLAME 100: 543-549 (1995)

Copyright (C) 1995 by The Combustion Institute

Published by Elsevier Science Inc. forces on the flow of the reaction products at some distance downstream of the nozzle, aerodynamic instabilities in the jet itself and heat release effects. Ellzey et al. [11] presented predictions both considering and neglecting gravity. They showed that neglecting gravity gave a steady flowfield but including gravity caused large structures to form that were convected downstream at frequencies on the order of $15-20 \mathrm{~Hz}$. An inviscid stability analysis for a buoyancy-driven flow in an infinite candle [12] predicted the frequency of the flickering within a factor of 2 . Hence, it appears that the relevance of gravity is significant for these types of flames.

Some work has been previously reported for laminar flames using fuel supplied as a liquid. A theoretical and experimental study [13] of a laminar diffusion spray flame did not encounter instabilities in the flame. Gravity was considered in this model, however, the model was derived only for steady-state conditions and consequently no instabilities were predicted. In addition, the liquid fuel was supplied directly from a nozzle as a conical spray that was surrounded by the combustion air, which is different from the Burke-Schumann configuration.

Studies by Greenberg [14-16] investigated the effects of fuel supplied as a liquid on the behavior of laminar diffusion flames in the 
Burke-Schumann configuration. In these studies, the central gaseous fuel jet used in the original formulation was replaced by liquid fuel droplets of various diameters carried by a flow of nitrogen. Effects of various initial velocity distributions, injection angles for the droplets, and preevaporation of the liquid fuel droplets were investigated. However, gravity was not included in these studies, and no instabilities in the flame behavior were predicted. An unsteady behavior of the flame was predicted [17], when gravity was neglected in the formulation, only when the fuel was supplied in a cosinusoidally alternating fashion of liquid and gas.

The present experimental study was motivated by the analytical study of Greenberg [14, 15] and Greenberg and Cohen [16, 17]. The objective of the present study was to experimentally investigate the effects of fuel droplet diameter, preevaporation of the liquid fuel and droplet trajectories on the structure of the flame in a Burke-Schumann configuration. The combustor utilized for the present study was a coaxial flow system flowing in the upward direction. The inner stream (fuel stream) contains fuel in the firm of liquid droplets and fuel vapor in different proportions. The fuel was carried in the upward direction by a nitrogen gas stream. Air flowed in the outer coflowing stream. Both the fuel and air streams had equal average velocities.

\section{EXPERIMENTAL APPARATUS}

The combustor was designed to study laminar spray combustion in an extension of the classical Burke-Schumann diffusion flame configuration. A schematic drawing of the combustor is illustrated in Fig. 1. The combustor consisted of two coaxial tubes. The outer tube was quartz and had an i.d. of $71 \mathrm{~mm}$. Two different inner tubes were utilized in the present study. A quartz inner tube was used for internal laser diagnostics, and had an i.d. of $12.90 \mathrm{~mm}$ and an o.d. of $14.80 \mathrm{~mm}$. A stainless steel tube with an i.d. of $12.54 \mathrm{~mm}$ and an o.d. of $15.80 \mathrm{~mm}$ was also used in the study when laser diagnostics were not required. The length (height) of the outer tube was $30 \mathrm{~cm}$. Tests with $100-\mathrm{cm}$ and

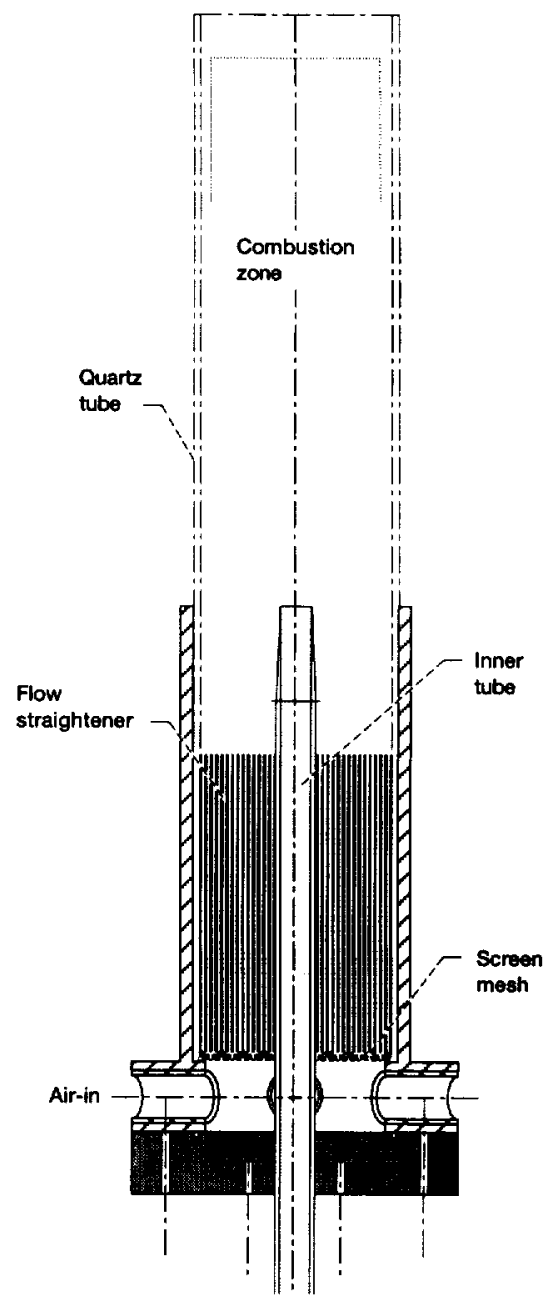

Fig. 1. Schematic drawing of the combustor.

$10-\mathrm{cm}$ length tubes or even without the outer tube, were performed to eliminate the possibility of acoustic coupling effects and showed negligible differences in behavior. As illustrated in Fig. 1, the combustion air entered through four radial entrance holes and passed through a series of fine-mesh screens and flow straighteners. The upstream length from the screens to the combustor (the tip of the center tube) was about $25 \mathrm{~cm}$ and the total length of the center tube (from the atomizer to the tip) was about $50 \mathrm{~cm}$.

Fuel was introduced into the combustor through the center tube in the form of fine droplets. A slightly modified Sonotek ultra- 
sonic nozzle \#8700-60 MS or a self-assembled ultrasonic unit were used to generate the droplets. As shown in Fig. 2, the droplets were injected upwards as a narrow conical spray. The droplets were then carried upwards by a nitrogen gas stream. The nitrogen was injected through a tube which surrounds the "horn" of the ultrasonic atomizer. As the droplets traveled upwards through the $50-\mathrm{cm}$ tube, they partially vaporized and interacted with each other, causing a subsequent change in their size and momentum. The large droplets were carried upwards at a velocity proportional to the difference between the nitrogen carrier gas flow and their Stokes velocity. The small droplets (less than 4 microns) can be used to represent the carrier gas velocity. This is illustrated in Fig. 3. Figure 3 presents centerline phase /Doppler data taken at axial locations of 300 and $20 \mathrm{~mm}$ below the exit of the center tube. Results are presented for droplet velocity and normalized drop number for droplet diameters up to $60 \mu \mathrm{m}$. Experimental uncertainty

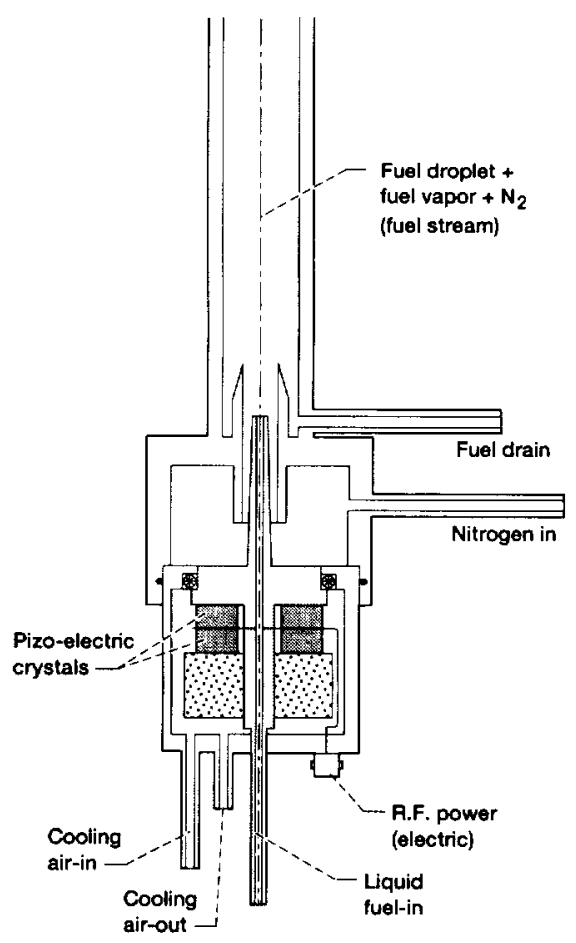

Fig. 2. Schematic drawing of the ultrasonic atomizer. in measurements for drop size is estimated at $\pm 6.5 \%$ and $\pm 0.5 \%$ for velocity. Flowrates of the nitrogen and fuel streams were maintained at $13.2 \times 10^{-6}$ and $12.0 \times 10^{-6} \mathrm{~kg} / \mathrm{s}$, respectively. Time resolved measurements of both the gas and drop velocities for up to $10 \mathrm{~s}$ inside the center tube indicated both to be steady. Heptane fuel was used for the results reported in the present paper.

Figure 4 presents velocity profiles for three drop sizes across the center tube at $20 \mathrm{~mm}$ upstream of the center tube exit at nearly the same conditions as Fig. 3. Flowrates of the nitrogen and fuel streams were $13.2 \times 10^{-6}$ and $14.0 \times 10^{-6} \mathrm{~kg} / \mathrm{s}$, respectively. The relatively low velocity of the carrier gas near the wall of the inner tube was not large enough to carry the larger drops. This caused them to descend and come into contact with the tube wall forming a liquid film that flowed downward. The number of droplets that hit the wall and the resulting flow in the downward direction was significant, especially in the lower part of the center tube. A drain was incorporated in the combustor configuration at the bottom of the center tube for continuous removal of the liquid film. The measurement of the actual fuel flow rate to the combustion zone always considered the drained amount.

Experimental measurements were obtained using two techniques. These included a twocomponent phase/Doppler particle analyzer (PDPA), which simultaneously measured the size and velocity of individual droplets, and a CCD camera coupled with laser light-sheet illumination for large-scale observations of the two-phase flow and flame. The average flame oscillation frequency was measured by the variation in gas velocity over a number of cycles in the combustion zone using measurements from the PDPA system.

\section{RESULTS AND DISCUSSION}

The oscillatory motion encountered in the present study is different from any reported previously in the literature. In this study, the entire volume of the flame was affected in an expansion/contraction type of modulation, whereas previously reported flame flickering affected 


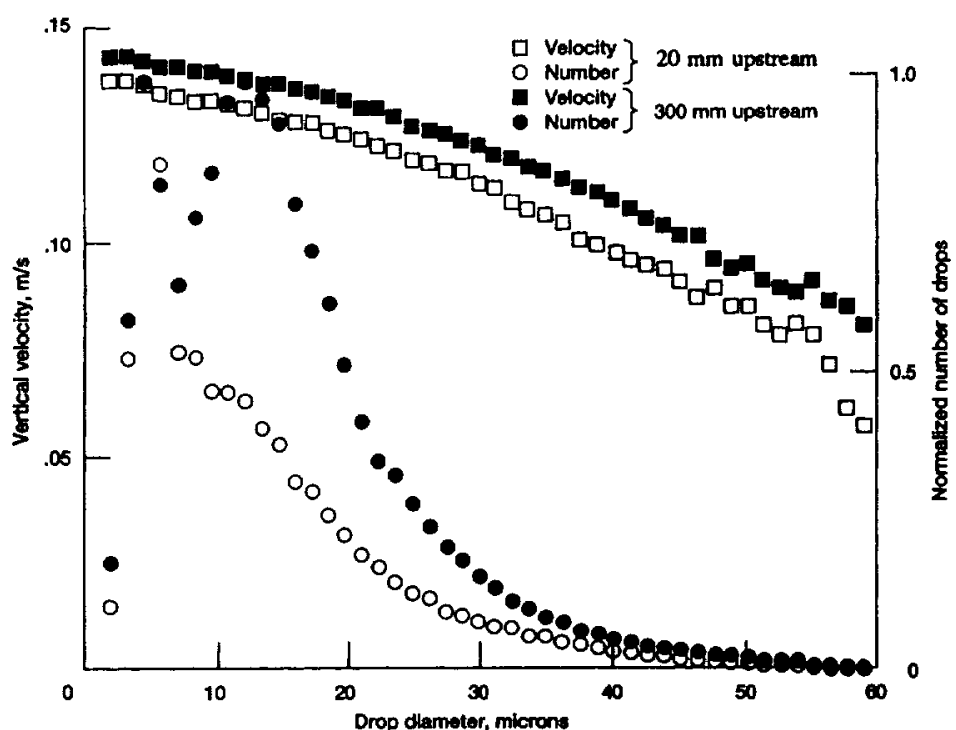

Fig. 3. Variation of centerline vertical velocity and number density with drop size at two axial locations inside the center tube. the flow of reaction products only at distances downstream of the nozzle.

Two sets of pictures are presented in Figs. 5 and 6 . Figure 5 illustrates the flame in a typical cycle of the phenomenon displayed in a complete view of the combustor and flame. The outer quartz tube and the inner stainless center tube are clearly visible. The flame is indicated by a blue color with a glowing soot tip. Flowrates of the air, nitrogen, and heptane streams were $107 \times 10^{-6}, 10.1 \times 10^{-6}$, and $2.84 \times 10^{-6} \mathrm{~kg} / \mathrm{s}$, respectively. Pictures are

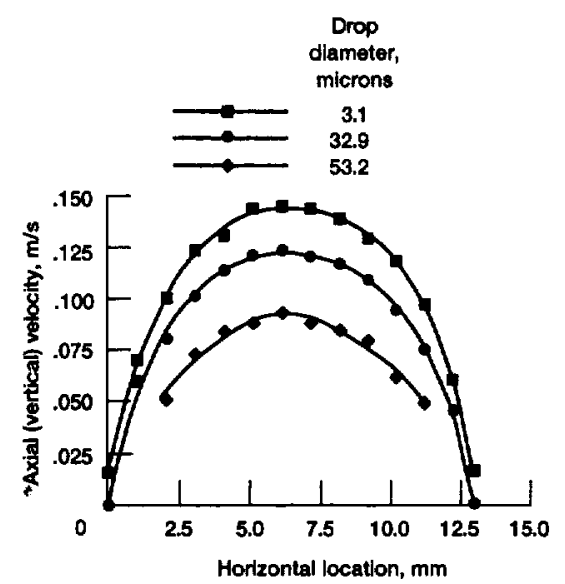

Fig. 4. Radial distribution of vertical velocity $20 \mathrm{~mm}$ upstream of the center tubc exit. marked by a video clock running at $30 \mathrm{~Hz}$, hence each clock increment corresponds to $33.3 \mathrm{~ms}$. For example the specific flame shown has an amplitude ratio (average ratio of minimum to maximum flame height) of about $1: 11$ and an average frequency of $3 \mathrm{~Hz}$. The frequency was obtained from time-resolved PDPA measurements over a number of cycles. A much closer view of the phenomena is given in Fig. 6, where the camera was focused to image closer to the exit of the center tube containing the fuel droplets and nitrogen. In Fig. 6, the flowrates of the air, nitrogen, and heptane streams were $119 \times 10^{-6}, 11.8 \times 10^{-6}$, and $13.5 \times 10^{-6} \mathrm{~kg} / \mathrm{s}$, respectively. It is evident that the equivalence ratio in Fig. 6 is much larger than in Fig. 5, 1.7 versus 0.4, however, the basic phenomena remained essentially identical except for absolute flame dimensions and frequency of oscillation. For flow visualization, the coflow air stream was seeded with aluminum oxide particles with a nominal size of $1 \mu \mathrm{m}$. The complete flowfield was illuminated by a light sheet (from left to right in the pictures) from an $\mathrm{Ar}^{+}$laser. The particles observed close to the center tube tip are the fuel droplets since the nitrogen stream was not seeded. The center tube was transparent quartz in order to provide optical access. The high- 

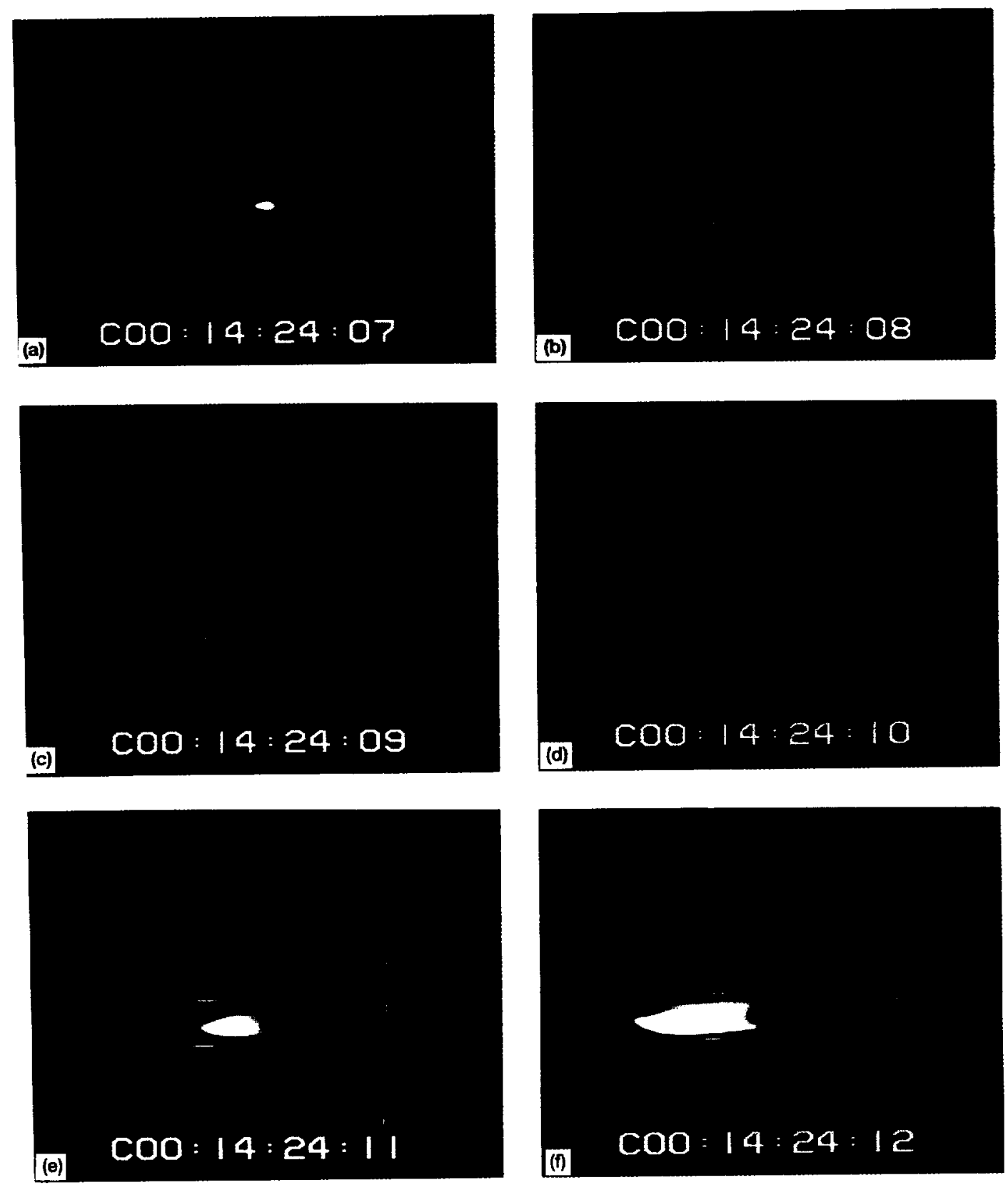

Fig. 5. Complete cycle of flame phenomenon. Test conditions: $107 \times 10^{-6} \mathrm{~kg} / \mathrm{s}$ air, $10.1 \times 10^{-6} \mathrm{~kg} / \mathrm{s}$ nitrogen, and $2.84 \times 10^{-6} \mathrm{~kg} / \mathrm{s}$ heptane. 

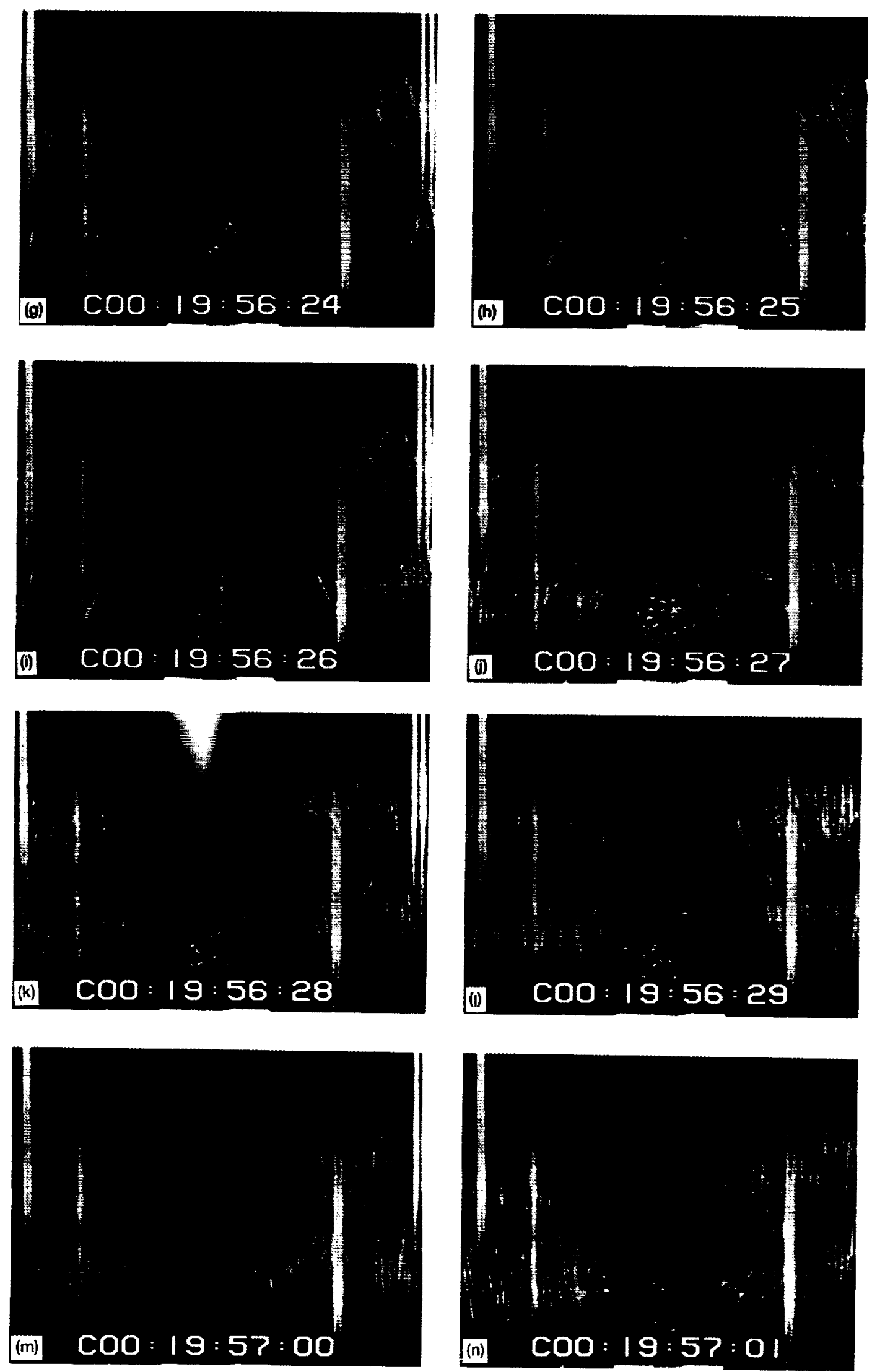

Fig. 5 Continued 

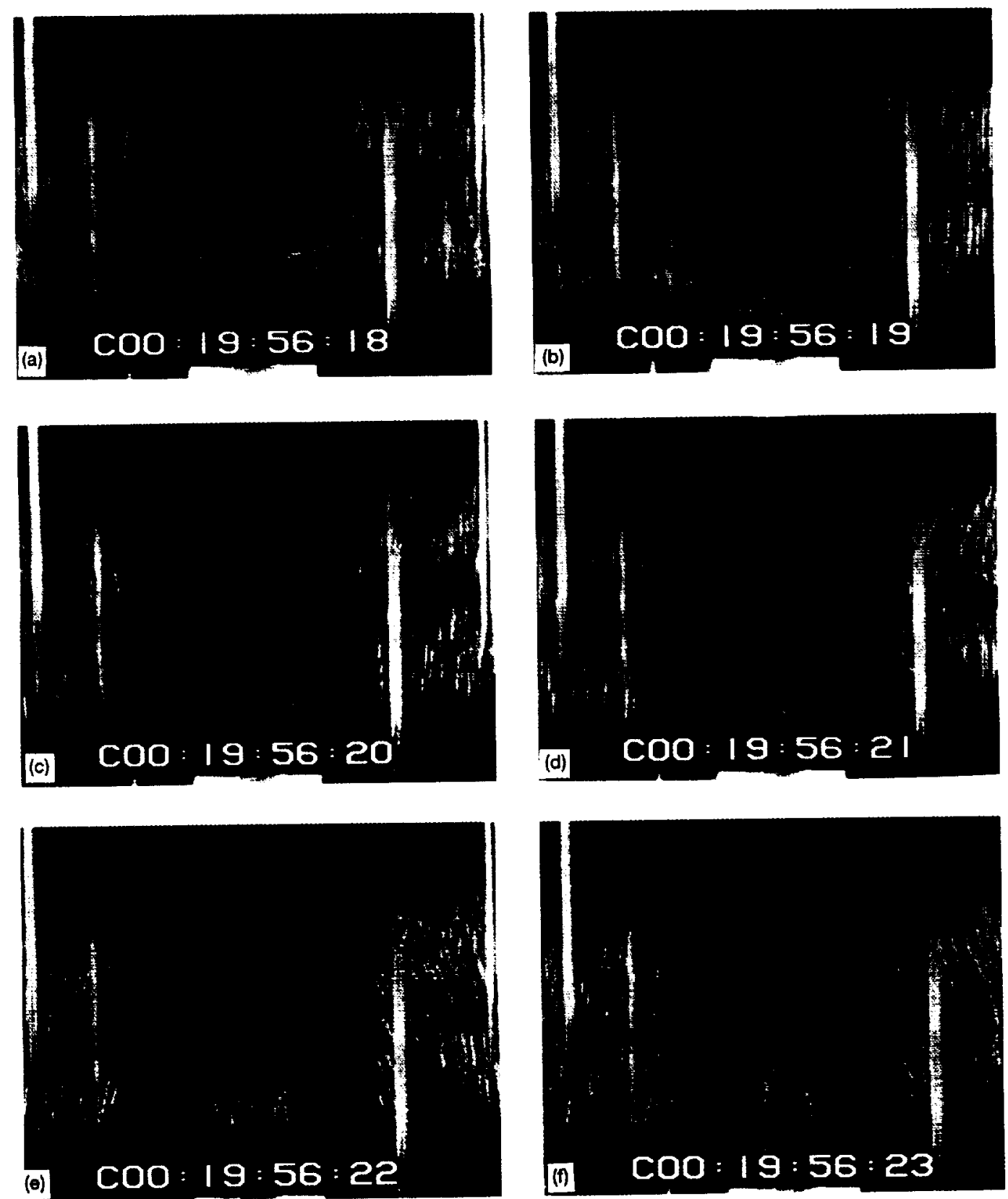

Fig. 6. Closeup view of flame phenomenon cycle with laser-sheet illumination and coflow air stream seeded. Test conditions: $119 \times 10^{-6} \mathrm{~kg} / \mathrm{s}$ air, $11.8 \times 10^{-6} \mathrm{~kg} / \mathrm{s}$ nitrogen, and $13.5 \times 10^{-6} \mathrm{~kg} / \mathrm{s}$ heptane. 

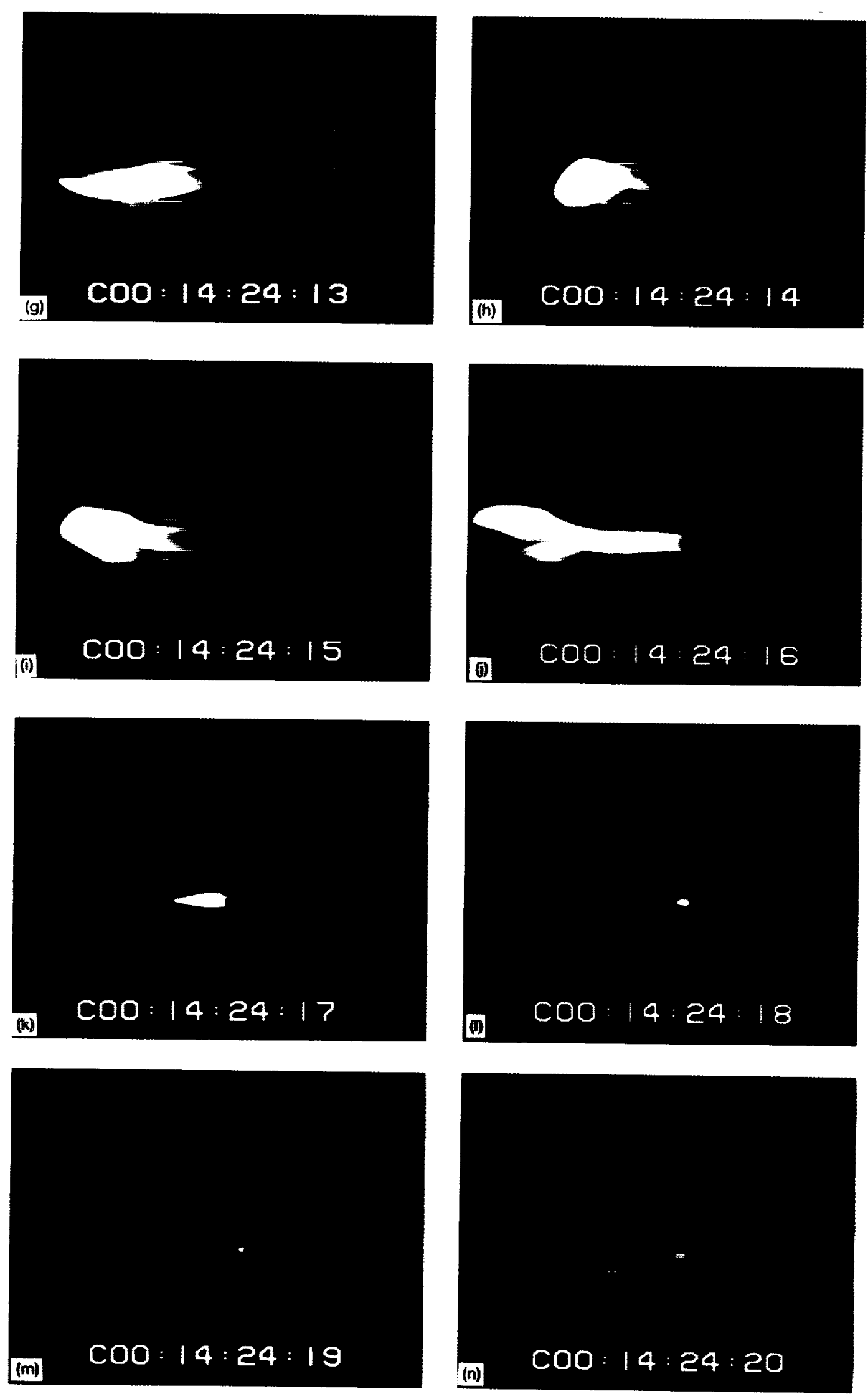

Fig. 6 Continued 
intensity illumination from the laser masks the blue flame color, however, the sooting tip is still clearly evident. As previously discussed, the flow conditions in Fig. 6 are not identical to those in Fig. 5; consequently, the average frequency shown here is $2.5 \mathrm{~Hz}$.

Except for two extreme cases of either very low velocities (up to about $0.01-0.02 \mathrm{~m} / \mathrm{s}$ ) or relatively high velocities (above about $0.3 \mathrm{~m} / \mathrm{s}$ ) of the nitrogen and air streams, the flame always exhibited an oscillatory motion when the fuel was supplied as a liquid. Both the flame dimensions and the frequency of the oscillations varied depending on the upstream flow conditions and ranged from $1-5 \mathrm{~Hz}$ for the frequency and 1:20 in amplitude ratio for the flame dimensions.

Following many sets of such photographs and local instantaneous size and velocity measurements performed with the phase/Doppler system, it is possible to establish a preliminary description of the phenomenon.

The oscillatory motion of the flame appears to originate from several coupled thermal and fluid mechanic mechanisms. A preliminary descriptive explanation of the mechanism and sequence of events within a cycle is proposed.

At the start of the cycle, before combustion commences, the fuel stream containing nitrogen, fuel droplets and fuel vapor flows upward in the center tube until it reaches the top of the center tube. After it emerges from the center tube, the fuel stream immediately expands radially outward and then flows downward creating a mushroom shaped cloud of nitrogen, fuel droplets and vapor. This is due to the significant density difference between the fuel stream and the surrounding coflowing air. The fuel stream is ignited by a descending flame which initiates the reaction between the fuel vapor and the adjacent oxygen (see Figs. $5 b$ and 6a). After ignition, the flame rapidly expands predominately in the radial direction (see Figs. 5c, 5d, 6b, and 6c), consuming the fuel vapor that exists at the interface between the top of the fuel stream and the coflow air. Thereafter, the flame spreads at a slower rate only in the vertical direction and the rate is now controlled by the evaporation rate of the fuel droplets (see Figs. $5 \mathrm{e}-5 \mathrm{j}$ and $6 \mathrm{~d}-6 \mathrm{i}$ ). Buoyancy effects lift the reaction products and, at a different rate, the emerging fuel stream. The fuel stream, which originally flowed radially outward and downward after emerging from the center tube, now acquires a vertical velocity component (see Fig. 6d-6i). This change is primarily due to heat transfer from the flame to the fuel stream by conduction and radiation. The height above the center tube that the fuel stream reaches appears to be a critical parameter in the dynamics of this flame. This height is determined by the velocities of the coflow and fuel streams.

The oxygen for reaction is available from two sources. The first source is radial diffusion inward from the surrounding coflow. This diffusion process must overcome the radial outward velocity of the newly generated reaction products. Oxygen is also available from a portion of the coflow air stream that manages to penetrate the combustion zone from the bottom of the flame, close to the center tube lip. This flow of oxygen is visualized by the laserlight scattered from the aluminum oxide seeding particles in the coflow air stream and is best seen in Figs. 6d-6f.

The fuel is consumed from the outer portion of the fuel stream nearest the flame, causing a reduction in the length and radius of the fuel stream (Figs. 6g, 6h). This rapid reduction in the radial dimension induces a short swirling motion (Figs. 6h, 6i), probably due to a temporal instability in the flow. The swirling motion is difficult to visualize from the photographs presented, distinguished only by horizontal lines from particle trajectories (Figs. 6h, 6i), however, it is quite evident when observing a videotape of the sequence of events. The consumption of fuel vapor in the fuel stream leads to a reduction in flame size (see Figs. $5 j-5 l$ and $6 j-61)$. This reduction in the flame size reduces the amount of heat transferred from the flame to the emerging fuel stream. Consequently, the fuel stream temperature is reduced causing a decrease in vertical velocity until negative values are observed (Figs. 6i-6k). A separation develops between the flame and the top of the decelerating fuel stream that prevents a fresh supply of fuel vapor from reaching the flame (see Figs. 6k, 6l).

The upward coflowing air now faces a descending semirigid center bluff body consisting 
of the relatively dense, droplet-laden fuel stream. Consequently, a toroidal recirculation zone is formed in the wake of the fuel stream with its center moving downwards (Figs. 61, $6 \mathrm{~m})$. This toroidal recirculation increases the radial spreading of the fuel stream (Figs. $6 \mathrm{~m}$, $6 n)$, reduces the position of the flame due to the reduced pressure at its center (Figs. 6a, 6b, $61,6 \mathrm{~m})$ and transfers fuel vapor from the top of the fuel stream upwards due to the upward velocity at the outer edge. The flame descends until it approaches the top of the emerging fuel stream which contains a large quantity of fuel vapor from vaporization of the droplets (Figs. 6b, 6n, 5b, 5m). The flame then expands rapidly again in the radial direction and the sequence of events is repeated from the beginning.

Hence, it appears that the modulation in the flame shape originates from the coupling between the flame and the fuel source. Although the fuel is supplied through the center tube in a steady fashion, confirmed experimentally with phase/Doppler measurements near the exit of the center tube, the region between the exit of the center tube and the flame is sufficient to allow for the fuel stream to periodically expand vertically and collapse radially, thus inducing the unique oscillatory motion observed. This phenomenon is altogether different from the flame flickering previously reported in the literature due to the large toroidal vortices generated by the buoyantly induced flow.

As previously discussed, at very low velocities, no oscillatory motion was encountered. In this case, the carrier gas velocity was sufficient to carry only the very small droplets, while the larger ones accumulated on the inner wall and drained out of the system. Because the small droplets evaporated almost completely prior to their entrance into the combustion zone, the fuel was essentially supplied in gaseous form and stable combustion was achieved. At the other extreme, higher velocities on the order of $0.3 \mathrm{~m} / \mathrm{s}$ also established a quasi-steady flame. For this case nearly all the generated droplets were carried upwards to the combustion zone. The resulting flame height was relatively constant with some random oscillations of smaller amplitudes and at higher frequencies. At the higher flowrates, the increased momentum of the coflow air stream prevented the collapse of the fuel stream as it emerged from the center tube. This increased the height above the center tube that the fuel stream reached providing increased residence time for droplet evaporation to occur. The higher velocities also increased the mixing of fuel vapor and air. In addition, at the higher velocities, a region of low velocity was formed in the wake of the central fuel stream that served to stabilize the flame.

\section{CONCLUSIONS}

A self-induced and continuous oscillatory motion, observed in liquid spray combustion with low velocities, is described. This phenomenon was observed over a relatively wide range of operating conditions and practically excludes the possibility of achieving laminar conditions in similar configurations.

A partially stable spray flame was achieved only at relatively high velocities where some turbulence in the flame structure was observed. A stable flame was also observed at extremely low velocities, but all droplets had vaporized by the time they reached the combustion zone. A preliminary descriptive explanation of the processes involved and supporting evidence are given.

\section{REFERENCES}

1. Burke, S. P., and Schumann, T. E. W., Indust. Eng. Chem. 20:998-1004 (1928).

2. Clarke, J. F., Inst. Math. Appl. 3:347-361 (1967).

3. Clarke, J. F., Proc. R. Soc. A. 307:283-302 (1968).

4. Chung, S. H., and Law, C. K., Combust. Sci. Technol. $37: 21-46$ (1984)

5. Durao, D. F. G., and Whitelaw, J. H., Proc. R. Soc. A. 338:479-501 (1974).

6. Toong, T. Y., Salant, R. F., Stopford, J. M., and Anderson, G. Y., Tenth Symposium (International) on Combustion, The Combustion Institute, Pittsburgh, 1965, p. 1301.

7. Kimura, I., Tenth Symposium (International) on Combustion, The Combustion Institute, Pittsburgh, 1965, p. 1295.

8. Ballantyne, A., and Bray, K. N. C., Sixteenth Symposium (Intemational) on Combustion, The Combustion Institute, Pittsburgh, 1976, p. 777. 
9. Chen, L. D., Seaba, J. P., Roqumore, W. M., and Goss, L. P., Twenty-Second Symposium (Intemational) on Combustion, The Combustion Institute, Pittsburgh, 1988 , p. 677.

10. Davis, R. W., Moore, E. F., Roqumore, W. M., and Chen, L. D., Combust. Flame 83:263-270 (1991).

11. Ellzey, J. L., Laskey, K. J., and Oran, E. S., Combust. Flame 84:249-264 (1991).

12. Buckmaster, J., and Peters, N., Twenty-First Symposium (International) on Combustion, The Combustion Institute, Pittsburgh, 1986, p. 1829.

13. Moore, J. G., and Moore, J., Sixteenth Symposium (International) on Combustion, The Combustion Institute, Pittsburgh, 1976, p. 1123.
14. Greenherg, J. B., Combust. Sci. Technol. 75:13-30 (1991).

15. Greenberg, J. B., Combust. Flame 77:229-240 (1989).

16. Greenberg, J. B., and Cohen, R., Atomiz. Sprays 2:275-293 (1992).

17. Grcenberg, J. B., and Cohen, R., Winter Annual Meeting of ASME on Heat and Mass Transfer in Spray Systems, Atlanta, Georgia, HTD, 1991, Vol. 187, p. 11.

18. Durst, F., Melling, A., and Whitelaw, J. H., Principle and Practice of Laser Doppler Anemometry, 2nd ed., Academic Press, London, 1981.

Recciled 5 April 199.3: retised Jume 1994 
- 